\title{
NUSAP1 promotes the metastasis of breast cancer cells via the AMPK/PPAR $\gamma$ signaling pathway
}

\author{
Juanjuan Qiu ${ }^{1,2 \#} \wedge$, Li Xu ${ }^{1 \#}$, Xiaohong Zeng ${ }^{1 \#}$, Zhenru Wu ${ }^{2}$, Yu Wang ${ }^{1}$, Yao Wang ${ }^{1}$, Jiqiao Yang ${ }^{1}, H_{a o} W^{1}$, \\ Yanyan Xie ${ }^{1}$, Faqing Liang ${ }^{1}$, Qing $\mathrm{Lv}^{1}$, Zhenggui $\mathrm{Du}^{1 \wedge}$ \\ ${ }^{1}$ Department of Breast Surgery, West China Hospital, Sichuan University, Chengdu, China; ${ }^{2}$ Key Laboratory of Transplant Engineering and \\ Immunology NHC, West China Hospital, Sichuan University, Chengdu, China \\ Contributions: (I) Conception and design: Z Du; (II) Administrative support: None; (III) Provision of study materials or patients: Q Lv, Z Du, F Qing, \\ Y Xie; (IV) Collection and assembly of data: Yu Wang, Z Wu, X Zeng; (V) Data analysis and interpretation: J Qiu, L Xu, Yao Wang; (VI) Manuscript \\ writing: All authors; (VII) Final approval of manuscript: All authors. \\ \#These authors contributed equally to this work. \\ Correspondence to: Zhenggui Du. Department of Breast Surgery, West China Hospital, Sichuan University, Chengdu, China. Email: docduzg@163.com.
}

Background: The biological function and molecular mechanism of nucleolar spindle-associated protein 1 (NUSAP1) in breast cancer remain controversial, this study aimed to reveal the mechanism of NUSAP1 in breast cancer cell metastasis and survival.

Methods: The expression of NUSAP1 expression was evaluated by immunohistochemistry and quantitative real-time polymerase chain reaction (RT-qPCR) in breast tissue samples. The correlation of NUSAP1 expression with the clinicopathological parameters of the patients and overall survival (OS) was evaluated. The protein expression was detected by Western blotting, the cell proliferation was evaluated by Edu staining and MTT assay, migration and invasion were tested by transwell and migration assay. Female BALB/c nude mice models for tumor growth and metastasis of breast cancer were evaluated in vivo.

Results: NUSAP1 is up-regulated in multiple cancers and is associated with a poor prognosis in breast cancer patients. Further analysis of the Gene Expression Omnibus (GEO) database and our included patients revealed that NUSAP1 expression gradually increased with pathological changes in breast tissue. Cell function assays confirmed that NUSAP1 was related to the proliferation, migration, and invasion of breast cancer cells. In vivo, NUSAP1 promoted lung metastasis in nude mice. We found that the NUSAP1 protein can promote tumor proliferation and metastasis by activating the AMPK/PPAR $\gamma$ signaling pathway.

Conclusions: Our findings show that NUSAP1 promotes breast cancer proliferation and metastasis by activating the AMPK/PPAR $\gamma$ signaling pathway.

Keywords: Breast cancer; nucleolar spindle-associated protein 1 (NUSAP1); AMPK; PPAR $\gamma$; proliferation; metastasis

Submitted Sep 27, 2021. Accepted for publication Nov 16, 2021.

doi: $10.21037 / \mathrm{atm}-21-5517$

View this article at: https://dx.doi.org/10.21037/atm-21-5517

^ ORCID: Juanjuan Qiu, 0000-0003-3852-5243; Zhenggui Du, 0000-0002-7412-0270. 


\section{Introduction}

The GLOBOCAN 2020 report of the International Agency for Cancer Research showed that breast cancer overtook lung cancer for the first time as cancer with the highest incidence rate worldwide (1). Local invasion and distant metastasis are the main risk factors associated with survival. There is no effective method to completely cure breast cancer metastasis, and prevention and control are the focus of treatment for metastatic breast cancer.

Nucleolar spindle-associated protein 1 (NUSAP1) has recently been recognized as a cell cycle regulating protein that binds microtubules and dominates mitotic progression, spindle formation, and stability $(2,3)$. The structural integrity of spindle ensures an equal division of the chromosomes, which can make a prerequisite for cell division. Abnormal spindle structure can result in wrong chromosome separation (also known as chromosomal instability), which will lead to tumorigenesis (4).

In recent years, with the in-depth study of NUSAP1, its biological function has been gradually identified. Several studies have shown that NUSAP1 plays an important regulatory role in tumors, including colorectal cancer $(5,6)$, prostate cancer (7), breast cancer (8), lung cancer $(9,10)$ and cervical cancer (11), and that a poor prognosis of breast cancer and melanoma may be significantly associated with high expression of NUSAP1 $(7,11,12)$. Further studies revealed that NUSAP1 plays an important role in cancer development, progression, and metastasis. For example, NUSAP1 is expressed in cervical cancer, and cancer stem cell traits and epithelial-mesenchymal transition progression can be enhanced by high expression of NUSAP1, resulting in cancer metastasis (13). A previous study confirmed that compared with normal tissue samples, NUSAP1 presented high expression in breast cancer tissue samples. In additional, NUSAP1 overexpression promoted the growth, migration, and invasion of MCF-7 cells (14). This study complemented the subcutaneous tumorigenesis and tail vein injection metastasis model in nude mice to make the study more reliable and complete. Furthermore, microarray analysis has revealed that NUSAP1 increased during from normal tissue to invasive ductal carcinoma, suggesting that NUSAP1 played an important role in tumor occurrence and progression perspective. These results suggest that high NUSAP1 expression is associated with the occurrence and progression of tumors.

The above results show that NUSAP 1 plays an important role in the development, survival, and metastasis of various cancers. However, the biological function and molecular mechanism of NUSAP1 in breast cancer remain controversial. This study aimed to reveal the mechanism of NUSAP1 in breast cancer cell metastasis and survival.

We present the following article in accordance with the ARRIVE reporting checklist (available at https://dx.doi. org/10.21037/atm-21-5517).

\section{Methods}

Breast cancer patient microarray gene expression data from Gene Expression Omnibus (GEO) and survival analysis

The expression profile GSE5364 was obtained from GEO (https://www.ncbi.nlm.nih.gov/geo/), a free and publicly available database. The set comprises 341 samples (270 tumors and 71 matched normal samples) from patients with breast, colon, liver, lung, esophageal, and thyroid cancer. We used the "limma" R package to detect NUSAP1 between breast cancer samples and normal breast tissue samples. Survival analysis was performed on the KaplanMeier Plotter website (15), whose sources for the databases included the GEO, the European Genome-Phenome Archive (EGA), and The Cancer Genome Atlas (TCGA).

\section{Tissue specimens and follow-up of patients}

The 80 breast cancer samples analyzed in our study were from patients who underwent surgery between August and November 2015 at the Department of Breast Surgery at the West China Hospital of Sichuan University (Chengdu, China). The other 30 pairs of breast cancer and adjacent tissues for quantitative real-time polymerase chain reaction (RT-qPCR) analyses were collected from patients who underwent surgery between June and July 2019 in the same hospital. Patients who had received neoadjuvant chemotherapy and those without a complete pathology diagnostic report were excluded. We also included 40 patients [10 usual ductal hyperplasia (UDH), 10 atypical ductal hyperplasia (ADH), 10 ductal carcinoma in situ (DCIS) and 10 invasive ductal carcinoma (IDC)] for tissue microarray analysis (the normal tissues were also from the $10 \mathrm{UDH}$ patients). Each patient was followed up every year to ensure reliable prognostic information. The study was conducted in accordance with the Declaration of Helsinki (as revised in 2013). All patients provided their written informed consent for inclusion before they participated in the study. The study was approved by the Ethics Committee 
of the Sichuan University [No. (2015)108].

\section{Cell culture}

Human breast cancer cell lines BT-474 and MDA-MB-231 were purchased from the American Type Culture Collection. Dulbecco's modified Eagle's medium (Invitrogen, USA) supplemented with $10 \%$ fetal bovine serum (Invitrogen, USA) was used to culture MDA-MB-231 cells, and RPMI 1640 (Invitrogen, USA) supplemented with 10\% fetal bovine serum was used for BT-474 cells. All cell lines were cultured in a humidified incubator at $37^{\circ} \mathrm{C}$ with $5 \% \mathrm{CO}_{2}$.

\section{RT-qPCR, immunobistochemistry, and Western blot}

RT-qPCR, western blotting, and immunohistochemistry were performed as previously reported (16). The following primers were used to amplify cDNA: NUSAP1: 5'-ATGAATGAACTGAAGCAGCCCA-3'; NC shRNA: 5'-ACTTAGGTGCGATACACGCTT-3' (Sangon Biotech, China), all sequences of used NUSAP1 shRNA and NC shRNA were showed in Table S1.

Immunohistochemistry was performed as previoussly reported (17). Primary antibodies (NUSAP1) coupled with an HRP-polymer kit (Maixin Biotechnology, China) were used, followed by incubation with 3,3'-diaminobenzidine for coloration. NUSAP1 was observed in breast cancer patients and pulmonary metastatic nodules of BALB/c nude mice. Immunohistochemical intensity scores were classified as follows: 0 , without staining; 1 , weak staining (light yellow); 2, moderate staining (yellow-brown); or 3, strong staining (brown); the percentage of stained cells was scored as follows: $0,<5 \% ; 1,6-25 \% ; 2,26-50 \% ; 3$, $51-75 \%$; or $4,76-100 \%$ positive cells (16). The total score was calculated by adding the density and percentage scores; high expression was defined as a total score of $\geq 4$, while low expression was defined as a total score of $<4$. Two pathological experts conducted the evaluation.

Proteins in breast cancer cell lines and tissues were extracted with the Membrane and Cytosol Protein Extraction Kit (Beyotime, China). Protein concentrations were determined with the Enhanced BCA Protein Assay Kit (Beyotime). In this study, NUSAP1 antibodies (Affinity, USA), AMPK (Thermo Fisher Scientific, USA), PPAR (Thermo Fisher Scientific, USA), $\beta$-actin antibodies (Affinity), and horseradish peroxidase conjugated anti-mouse secondary antibodies (Santa Cruz Biotechnology, USA) were applied.

\section{Transfection}

Lentiviral vectors containing NUSAP1 shRNA, NC shRNA, and NUSAP1 OE plasmid were obtained from HanBio (China) and transfected into cells by following the manufacturer's instructions. Stable cells transfected with lentivirus were tested with puromycin $(2 \mu \mathrm{g} / \mathrm{mL})$ for use in subsequent experiments.

\section{Cell proliferation, migration, and invasion assay}

The MTT assay measured Cell proliferation (Beyotime Biotechnology, China) and the EdU assay (Ribo Life Science, China). In the Cell Counting Kit-8 (CCK-8) assay, MDA-MB-231 and BT-474 cells $\left(1.0 \times 10^{3} /\right.$ well $)$ were seeded in a 96-well plate. After $0,24,48,72$, and $96 \mathrm{~h}$ of incubation, cells were washed with PBS and dimethylsulfoxide was used to dissolve the purple formazan product. Then, $10 \mu \mathrm{L}$ MTT was added to each well for $2 \mathrm{~h}$. The absorbance of the resulting solution was assessed at a wavelength of $450 \mathrm{~nm}$ with a microplate reader (Thermo Scientific, USA). For the EdU assay, cells were subcultured in a 24-well plate for 1 day. The cell-Light EdU Apollo567 In Vitro Imaging Kit (RiboBio, China) was used for the EdU incorporation assay following the manufacturer's instructions $48 \mathrm{~h}$ after transfection. Images were captured under the fluorescence microscope.

Wound healing assays evaluated MDA-MB-231 cells. The cell line was seeded in six-well plates and scratched with a sterile pipette tip, and then the cells were washed with PBS. DMEM containing 5\% FBS was added to each well. The images were sequentially captured at 0,24 , and $48 \mathrm{~h}$ of cultivation. The same areas of each wound were sequentially captured and the relative migration rate of the fused cells was calculated. The Transwell assay determined the migration ability of BT-474 cells due to their special growth characteristics. For BT-474 cells, migration assays, $6 \times 10^{4}$ cells suspended in $200 \mu \mathrm{L}$ serum-free medium were added to the upper chamber of Transwell, each of which included a Tewksbury multi-porous polycarbonate membrane $(8-\mathrm{mm}$ pore size) insert, and medium containing $10 \%$ FBS was placed as a chemical attractant at the bottom of the chamber.

According to the manufacturer's instructions, cell invasion was detected using a Transwell chamber coated with Matrigel (1:100 in DMEM; BD Biosciences, USA). The $2 \times 10^{5}$ cells in serum-free medium were added to the upper chamber, and the lower chamber contained $500 \mu \mathrm{L}$ of $20 \%$ 
FBS-supplemented medium. After culturing for $24 \mathrm{~h}$, the cells were fixed with $4 \%$ paraformaldehyde for $30 \mathrm{~min}$. The migrated cells were stained with crystal violet for $20 \mathrm{~min}$ and washed with PBS three times.

\section{Animal studies}

Twenty female BALB/c nude mice (4-5 weeks old) were purchased from Gem Pharmatech (Nanjing, China). All animal studies and procedures followed ethical guidelines and were approved by the Sichuan University Animal Ethics Committee (No. [2020]203), in compliance with the current national guidelines for Animal Welfare of China (GB/T 35892-2018) for the care and use of animals. A protocol was prepared before the study without registration. All mice were maintained on a regular diurnal lighting cycle (12:12 light:dark) with ad libitum access to food and water at a temperature of 22 to $26^{\circ} \mathrm{C}$. Wood shavings was used as bedding. The weight loss caused by tumor overload was logged as "adverse events" in the experiment, which would terminate the experiment and the mice was immediately killed. The sample size was determined from a similar experiment reported in the literature $(15,17)$. Animals were excluded if the animal died prematurely, preventing tumor and lung collection. For the subcutaneous inoculation model, ten mice were randomly divided into two groups (5 mice/group): the NC group and the KD group, $1 \times 10^{7}$ cells in $200 \mu \mathrm{L}$ PBS were injected subcutaneously into the right dorsal flank, random numbers were generated using the standard = RAND() function in Microsoft Excel (18). The mice were sacrificed and tumor volume was measured after 6 weeks; the formula calculated tumor volume:

$$
\text { Tumor volume }=\frac{\pi}{6} \times L \times W^{2}
$$

where $\mathrm{L}$ is the longest diameter and $\mathrm{W}$ is the shortest diameter of the excised tumor. For the metastasis model, the grouping method is the same as before; $2 \times 10^{6}$ cells in $200 \mu \mathrm{L}$ PBS were injected into the tail veins of 6 -week-old female nude mice. The mice were sacrificed after 6 weeks, and the tumor nodules formed in the lungs were embedded in paraffin for H\&E staining and counted. No animals were excluded from this study. Three different investigators were involved in this study as follows: the first investigator injected cells, who was aware of the allocation of the treatment group. The second investigator performed the surgical procedure, while the third analyzed the data.

\section{Statistical analysis}

SPSS 20.0 software (IBM Corporation, Armonk, NY, USA) was used for statistical analyzes. Data are presented as mean \pm standard deviation and were compared using the Student's $t$ test or analysis of variance. Survival curves were estimated using the Kaplan-Meier method and the logarithmic rank test was used to assess the difference in survival curves. $\mathrm{P}<0.05$ (two-sided) was considered statistically significant.

\section{Results}

\section{The expression of NUSAP1 in multiple tumors, including} breast cancer

GEO database analysis showed that NUSAP1 was one of the hub genes in multiple cancers (breast, colon, liver, lung, esophageal, and thyroid cancer) (Figure $1 A$ ). In various tumors, NUSAP1 was highly expressed in tumor tissues compared to adjacent tissues (Figure $1 B$ ), which was also verified in breast cancer (Figure 1C). Furthermore, we assessed the expression of NUSAP1 in 30 breast cancer tissues and adjacent tissues using RT-PCR. As expected, the expression of NUSAP1 mRNA was higher in breast cancer tissues than in adjacent tissues (Figure 1D).

In the analysis of the other 80 breast cancer tissues, we found that the expression of NUSAP1 was associated with diameter $(\mathrm{P}=0.039)$, estrogen receptor status $(\mathrm{ER})(\mathrm{P}=0.024)$, progesterone receptor status $(\mathrm{PR})(\mathrm{P}=0.038), \mathrm{Ki} 67$ $(\mathrm{P}=0.011)$, molecular phenotype $(\mathrm{P}<0.001)$ and lymph node metastasis $(\mathrm{P}=0.008)$ (Table 1); 59\% (29/49) of patients with high expression of NUSAP1 were diagnosed with lymph node metastasis, and $83 \%$ (20/24) of patients with lymph node metastasis had high expression of NUSAP1, indicating that NUSAP1 could promote metastasis and prognosis of breast cancer.

\section{The gradual increase in NUSAP1 expression with breast tissue pathological changes and its infuence on the overall survival (OS) and recurrence-free survival (RFS) of breast cancer patients}

To investigate the potential role of NUSAP1 in breast cancer progression, we examined the expression of NUSAP1 in different pathological types of breast tissue. Compared with that in normal breast tissue, the expression of NUSAP1 increased stepwise in UDH, ADH, and DCIS, according to GEO database analysis. The expression of 
A

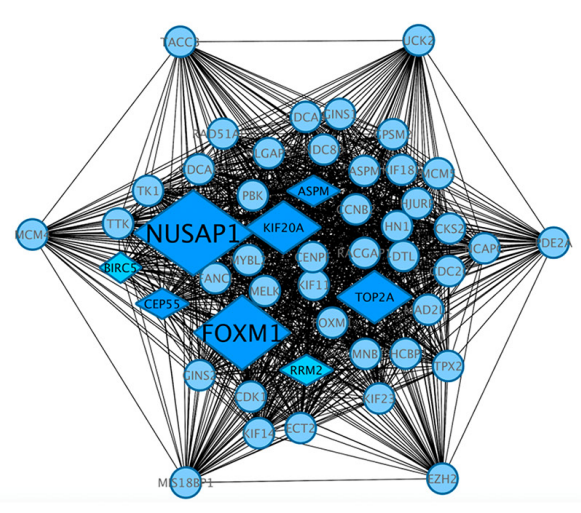

C

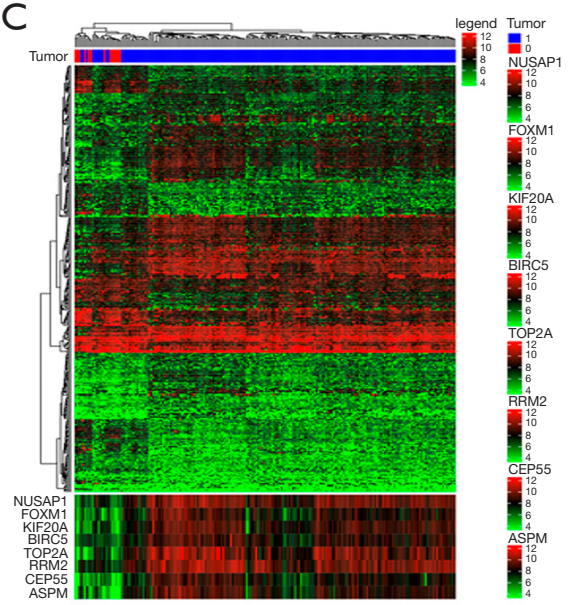

B

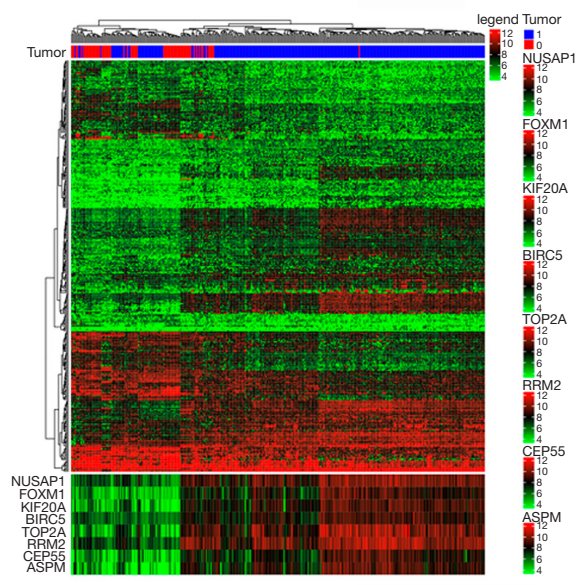

D

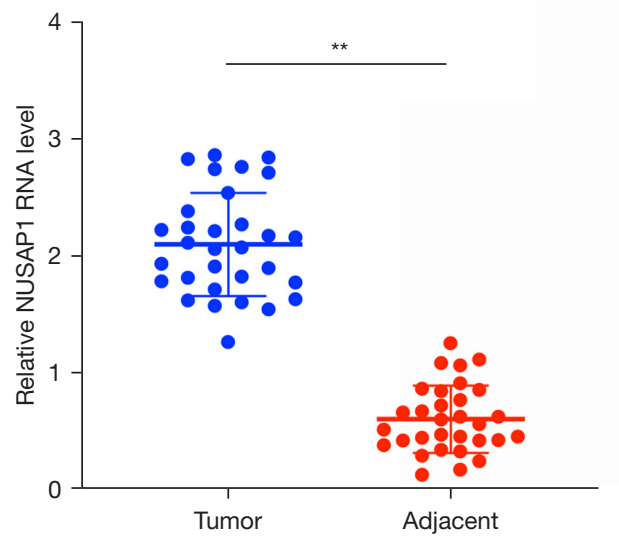

Figure 1 NUSAP1 expressed highly in a variety of tumors. (A) NUSAP1 was one of the hub genes in multi-cancer (breast, colon, liver, lung, oesophagal and thyroid cancer) progression in GEO database; NUSAP1 in tumor tissues was higher than that in adjacent tissues in multi-cancer (B) and in breast cancer (C) in GEO database. (D) NUSAP1 mRNA expression in breast cancer tissues and adjacent tissues. **, $\mathrm{P}<0.01$. NUSAP1, nucleolar spindle-associated protein 1; GEO, Gene Expression Omnibus.

NUSAP1 in IDC was slightly lower than that in DCIS, but was still significantly higher than that in other tissue types (Figure $2 A, 2 B$ ). To verify this conclusion, we stained a tissue microarray of normal breast, UDH, ADH, DCIS, and IDC tissues and obtained a similar conclusion (Figure 2C,2D).

We analyzed the effect of NUSAP1 expression on the prognosis of breast cancer patients by using online tools. The results showed that patients with high expression of NUSAP1 had worse OS and RFS than patients with low expression (P value was $1.9 \times 10^{-7}$ and $<1 \times 10^{-16}$, respectively) (Figure $3 A, 3 B$ ). Kaplan-Meier analysis of the 80 breast cancer patients was performed and yielded a similar conclusion ( $\mathrm{P}$ values were 0.037 and 0.047 , respectively) (Figure 3C,3D).

\section{NUSAP1 significantly affected the proliferation of breast cancer cell lines}

To detect the roles of NUSAP1 in breast cancer, we first detected NUSAP1 expression in breast cancer cell lines with differences in ER, PR, and HER2 status. The expression of NUSAP1 was higher in the MDA-MB-231 breast cancer cell line and lower in the BT-474 cell lines than in other cell lines (Figure 4A). Then, gain-of-function 
Table 1 Demographic characteristics and association between NUSAP1 expression and clinicopathological features

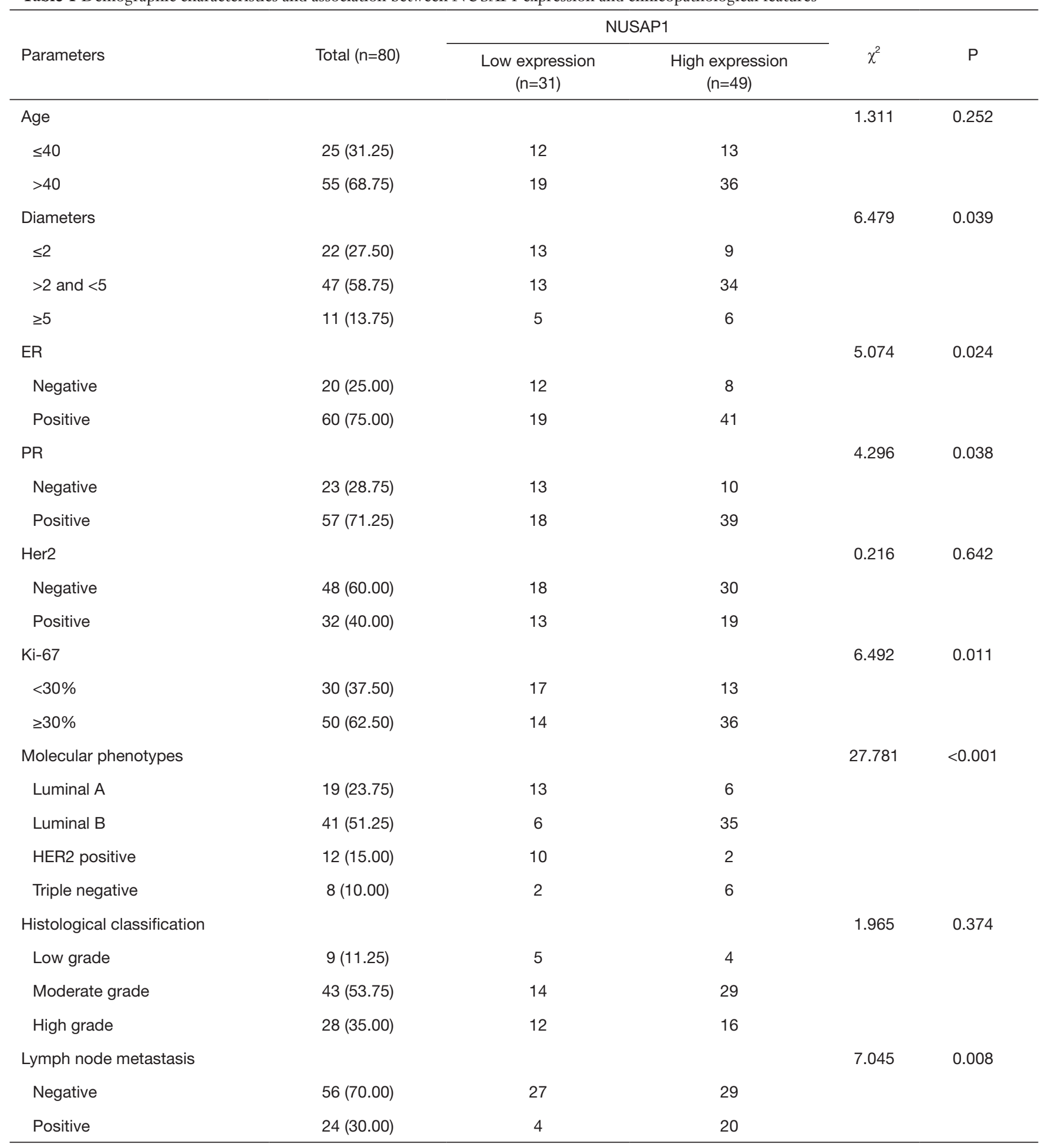

ER, estrogen receptor; PR, progesterone receptor; HER2, human epidermal growth factor receptor 2. 
A

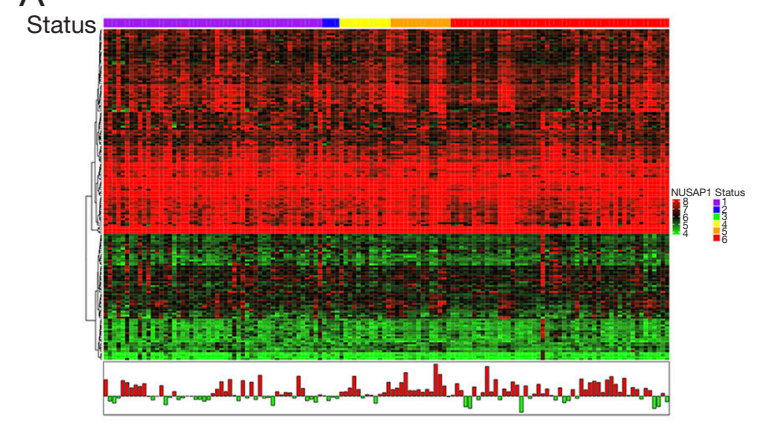

C

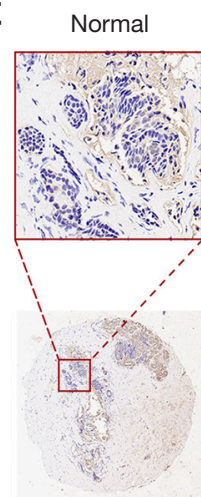

$\mathrm{UDH}$

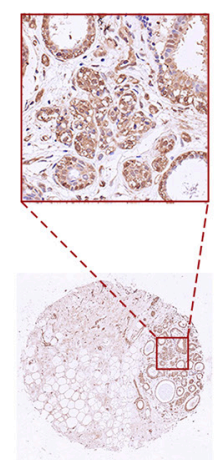

$\mathrm{ADH}$

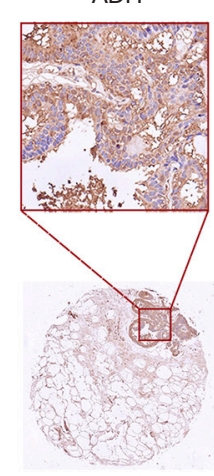

B

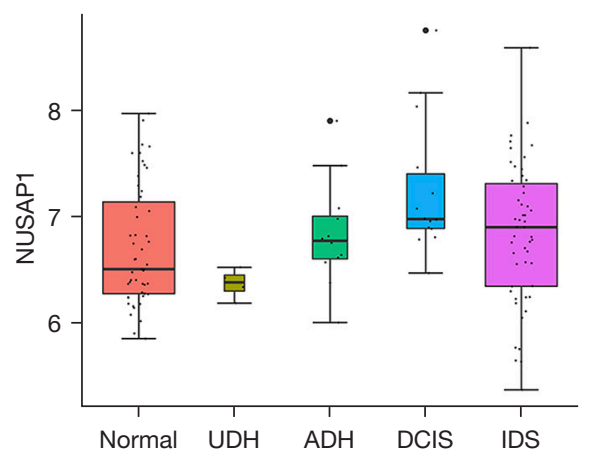

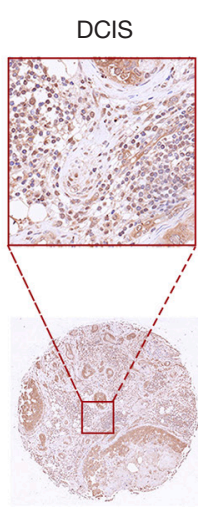
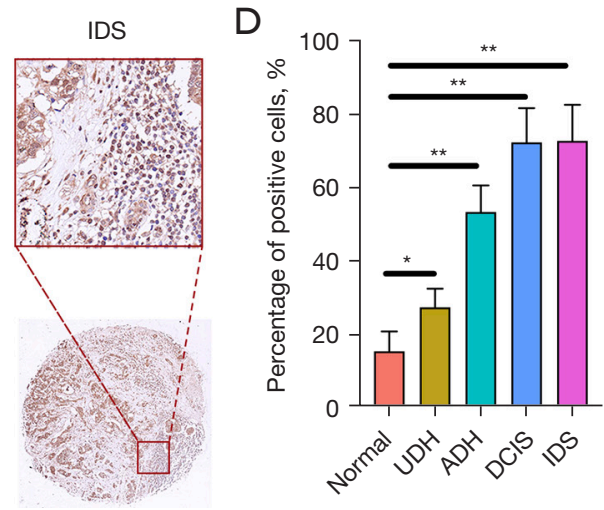

Figure 2 The expression of NUSAP1 increased gradually in normal breast tissue, UDH, ADH, DCIS and IDC. Compared with normal breast tissue, the expression of NUSAP1 in UDH, ADH and DCIS increased gradually and in IDC was also higher than other types in GEO database (A,B); immunohistochemical validation of tissue microarray results showed that NUSAP1 expression increased gradually from normal breast tissue to DCIS and IDC $(\mathrm{C}, \mathrm{D})(\times 40)$. * $\mathrm{P}<0.05$; **, $\mathrm{P}<0.01$. NUSAP1, nucleolar spindle-associated protein 1 ; UDH, usual ductal hyperplasia; ADH, atypical ductal hyperplasia; DCIS, ductal carcinoma in situ; IDC, invasive ductal carcinoma; GEO, Gene Expression Omnibus.

and loss-of-function methods were used. We generated stable MDA-MB-231 and BT-474 cells with NUSAP1 knockdown (KD) or overexpression (OE). Western blotting was conducted to verify the protein expressions of NUSAP1 after transfection (Figure 4B). Subsequently, we further assessed cell proliferation. MTT and 5-ethynyl-2'deoxyuridine (EdU) assays showed that KD of NUSAP1 remarkably inhibited the growth of breast cancer cells compared with cells without transfection. However, OE of NUSAP1 significantly enhanced the proliferation of breast cancer cells (Figure 4C,4D).

\section{NUSAP1 significantly affected the migration and invasion of breast cancer cell lines}

We evaluated the impact of NUSAP1 on the migration and invasion of MDA-MB-231 and BT-474 cells. Wound healing assays evaluated the migration of MDA-MB-231 cells, and Transwell assays evaluated the migration of BT474 cells. Transwell assays evaluated the invasion of MDAMB-231 and BT-474 cells. The results showed that the migration and invasion ability of MDA-MB-231 cell lines decreased after NUSAP1 KD $(\mathrm{P}<0.05$; Figure $5 A, 5 B)$, while NUSAP1 OE significantly enhanced the migration and invasion of BT-474 cells $(\mathrm{P}<0.05$; Figure $5 C, 5 D)$.

\section{Knockdown of NUSAP1 inbibited breast cancer growth in vivo}

To further verify the effect of NUSAP1 on breast cancer tumorigenesis in vivo, we established subcutaneous tumor and tail vein metastasis models in BALB/c-nu nude mice. MDA-MB-231-NUSAP1-KD and MDA-MB-231-NC cells were injected subcutaneously or via the tail vein. After 
A
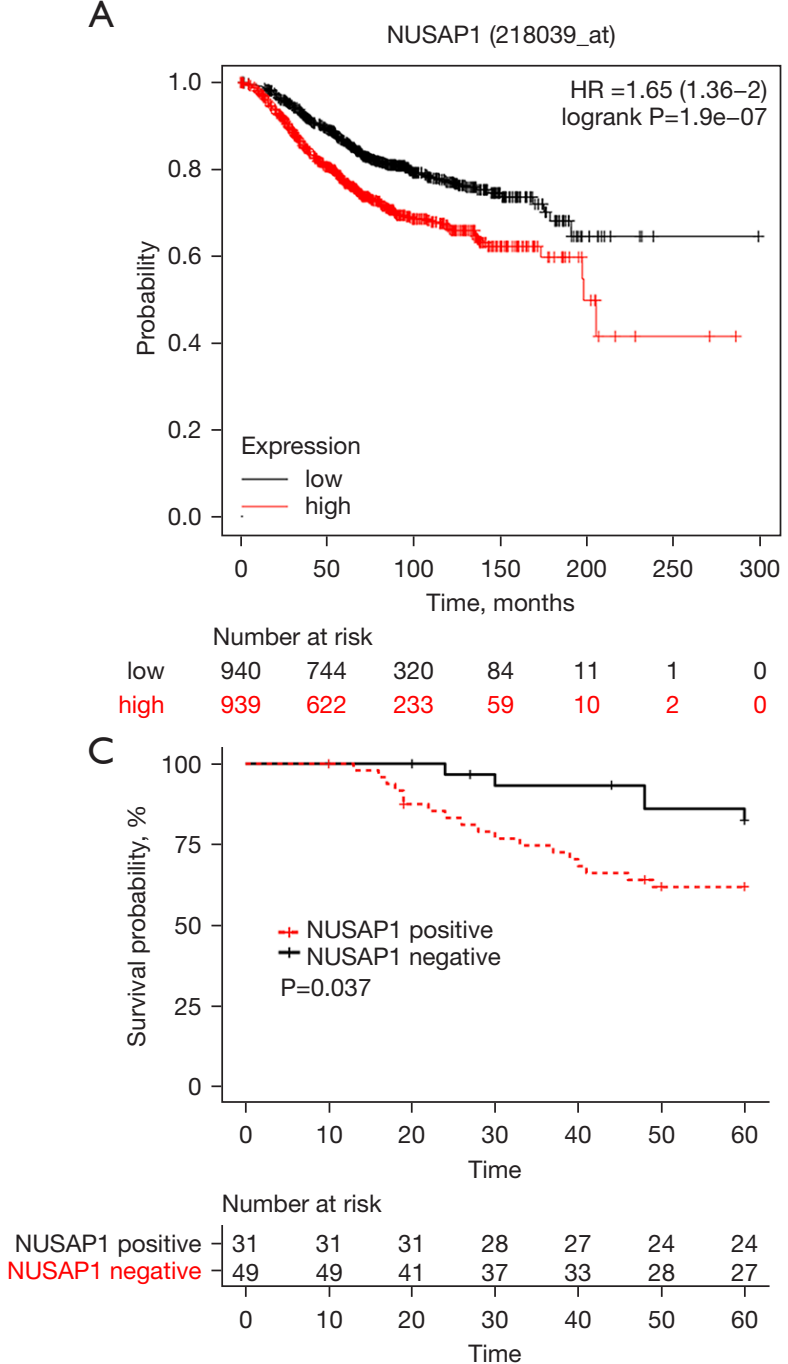

B
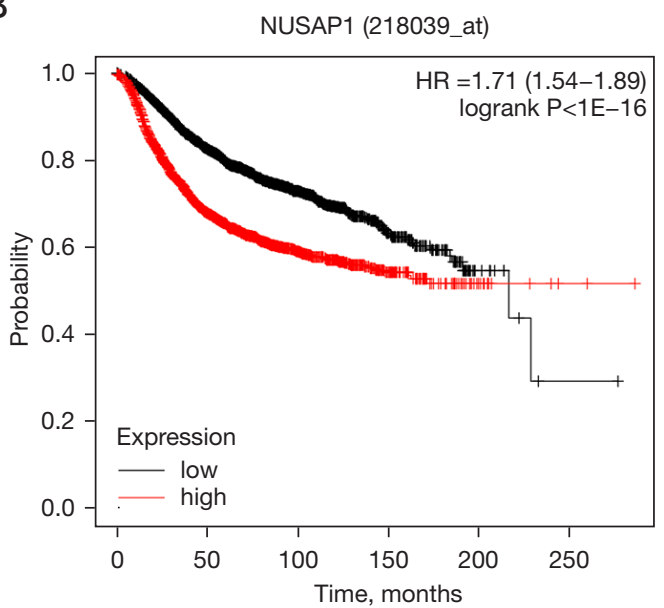

Number at risk

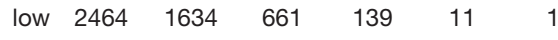

high $\begin{array}{llllll}2465 & 1249 & 475 & 107 & 16 & 2\end{array}$

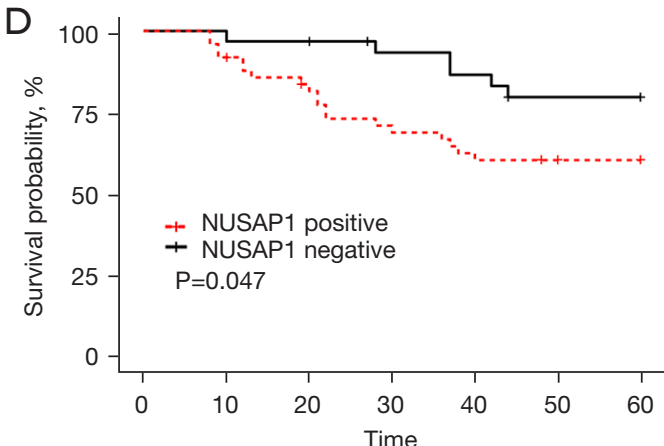

Number at risk

\begin{tabular}{|c|c|c|c|c|c|c|c|}
\hline NUSAP1 positive & 31 & 31 & 30 & 27 & 25 & 22 & 22 \\
\hline NUSAP1 negative & 49 & 45 & 39 & 33 & 29 & 27 & 26 \\
\hline & 0 & 10 & 20 & 30 & 40 & 50 & 60 \\
\hline
\end{tabular}

Figure 3 Positive expression of NUSAP1 was associated with poor OS and RFS in patients with breast cancer in GEO, EGA, and TCGA database (A,B), the similar results were found in our included breast cancer patients (C,D). NUSAP1, nucleolar spindle-associated protein 1; OS, overall survival; RFS, relapse free survival; GEO, Gene Expression Omnibus; EGA, European Genome-Phenome Archive; TCGA, The Cancer Genome Atlas.

42 days, mice were sacrificed, and the subcutaneous tumors and lungs were enucleated and analyzed.

The results revealed that NUSAP 1 KD could significantly inhibit tumor growth (NC and KD group were 953.0 $\pm 100.6,513.6 \pm 156.3$, respectively) (Figure 6A, $\mathrm{P}=0.0011$ ), and western blotting confirmed nUSAP1 expression after isolating the tumor at the end of the seventh week (Figure $6 B$ ). NUSAP1 KD also strongly suppressed the metastasis of MDA-MB-231 cells (Figure 6C), which was further confirmed by counting the visible metastatic lesions by hematoxylin and eosin (H\&E) staining
(NC and KD group were $24.4 \pm 8.9,13.0 \pm 4.9$, respectively) (Figure $6 D, \mathrm{P}=0.0354)$. Immunohistochemistry confirmed the expression of NUSAP1 expression (Figure 6E).

\section{NUSAP1 activates the AMPK/PPAR patbway in breast cancer cells}

The Kyoto Encyclopedia of Genes and Genomes (KEGG)/ Gene Ontology (GO) analysis of differentially expressed genes was used to explore the mechanism by which NUSAP1 promotes breast cancer progression. Specifically, 
A

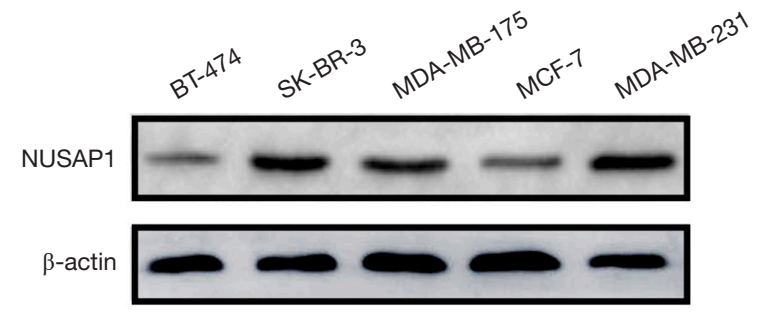

B

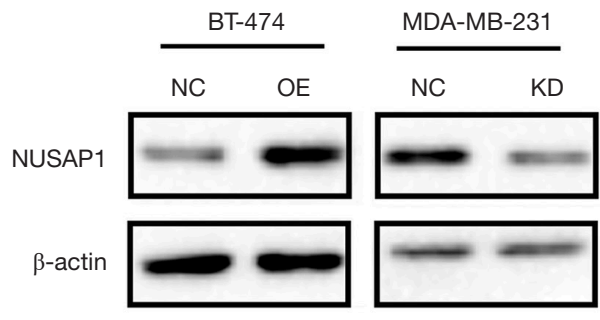

C

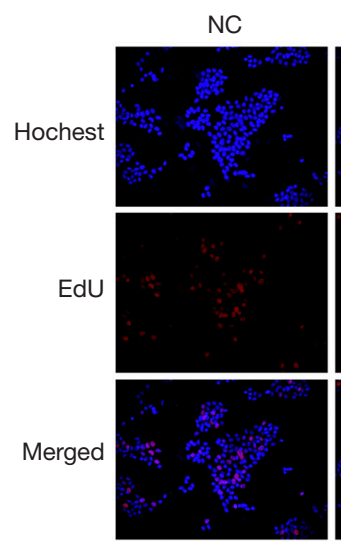

BT-474

OE

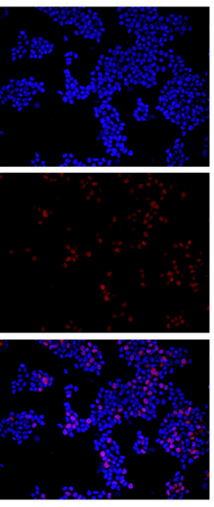

D

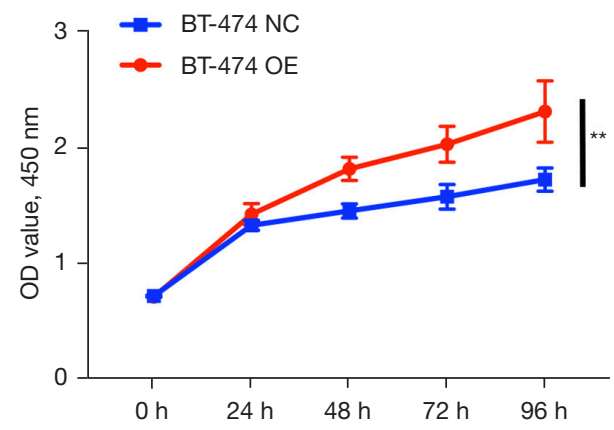

MDA-MB-231
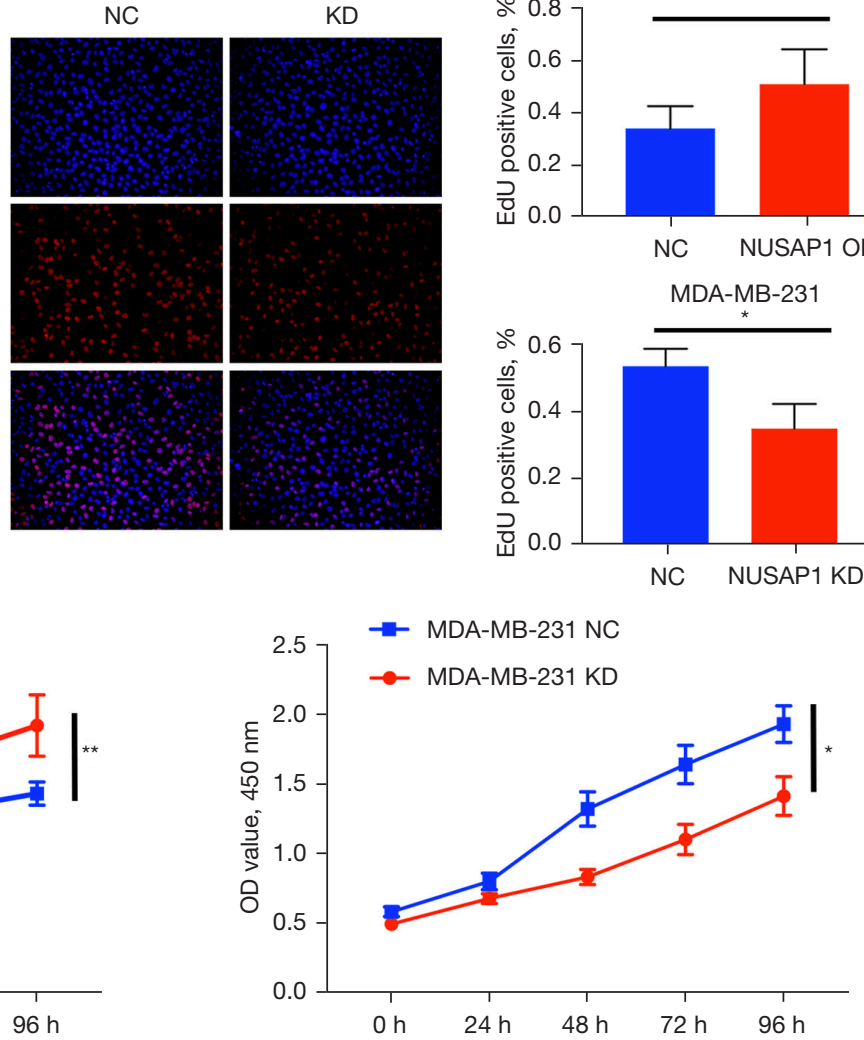

Figure 4 NUSAP1 affected proliferation of breast cancer cells. (A) NUSAP1 expression in different breast cancer cell lines; (B) Western blotting was performed to verify the protein levels of NUSAP1 after transfection; EDU (C) ( $\times 50)$ and MTT (D) assay were performed in stable KD or OE NUSAP1 group of MDA-MB-231 and BT-474 cell lines. * $\mathrm{P}<0.05 ;{ }^{* *}, \mathrm{P}<0.01$. NUSAP1, nucleolar spindle-associated protein 1; NC, negative control; OE, overexpression; KD, knockdown.

465 downregulated genes and 188 upregulated genes were selected for further analysis. The results indicated that NUSAP1 affected PPAR signaling, metabolic pathways, fatty acid pathways, etc. (Figure $7 A$ ). The AMPK/PPAR pathway is related to cell metabolism (18-21), which could affect the occurrence and development of tumors. Thus, to elucidate whether the AMPK/PAR pathway is involved in NUSAP1-induced breast cancer progression, Western blotting examined the expression of AMPK and PPAR $\gamma$ in MDA-MB-231-NUSAP1-KD cells, MDA-MB231-NC cells, BT-474-NUSAP1-OE cells and BT-474NC cells. Figure $7 B$ shows that AMPK and PPAR $\gamma$ were downregulated in NUSAP1-KD cell lines and upregulated in NUSAP1 OE cell lines. In summary, the pathway by 
A

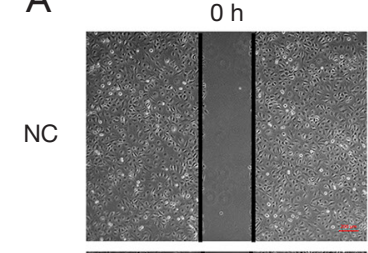

$\mathrm{KD}$

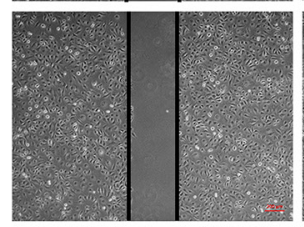

B
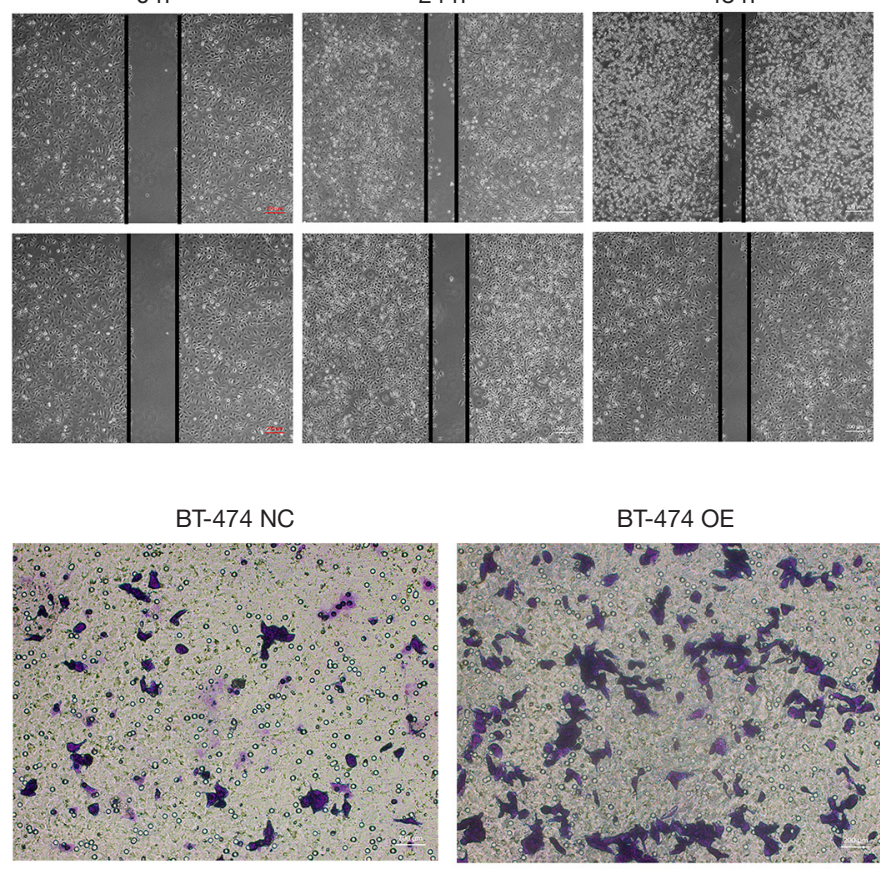

BT-474 OE

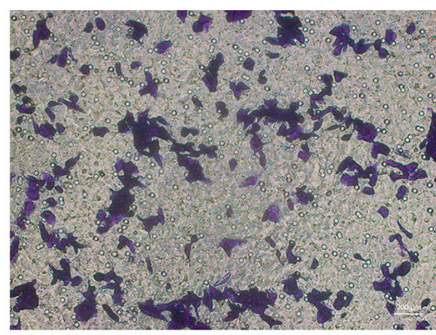

C
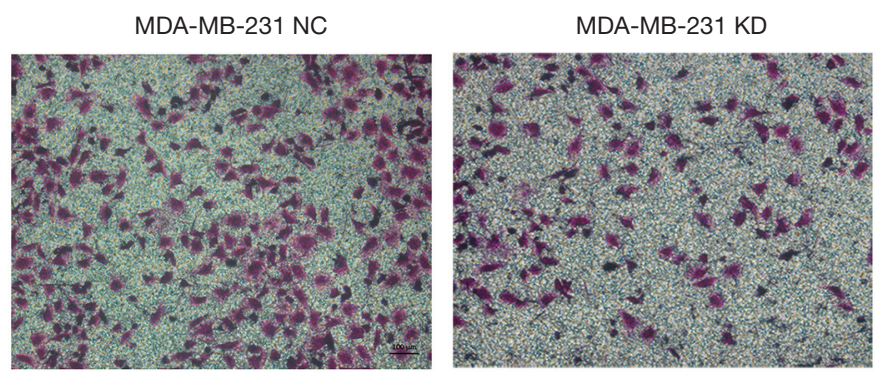

D

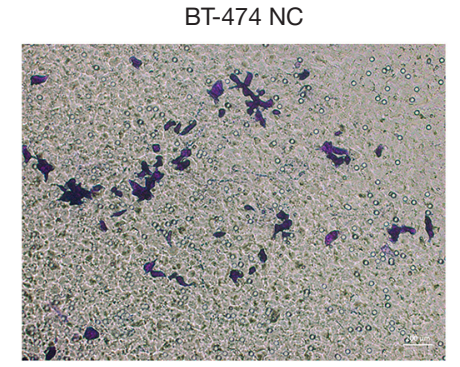

$48 \mathrm{~h}$

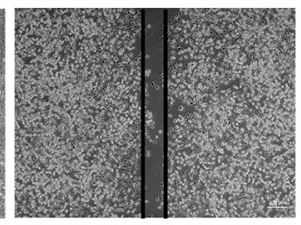

BT-474 OE
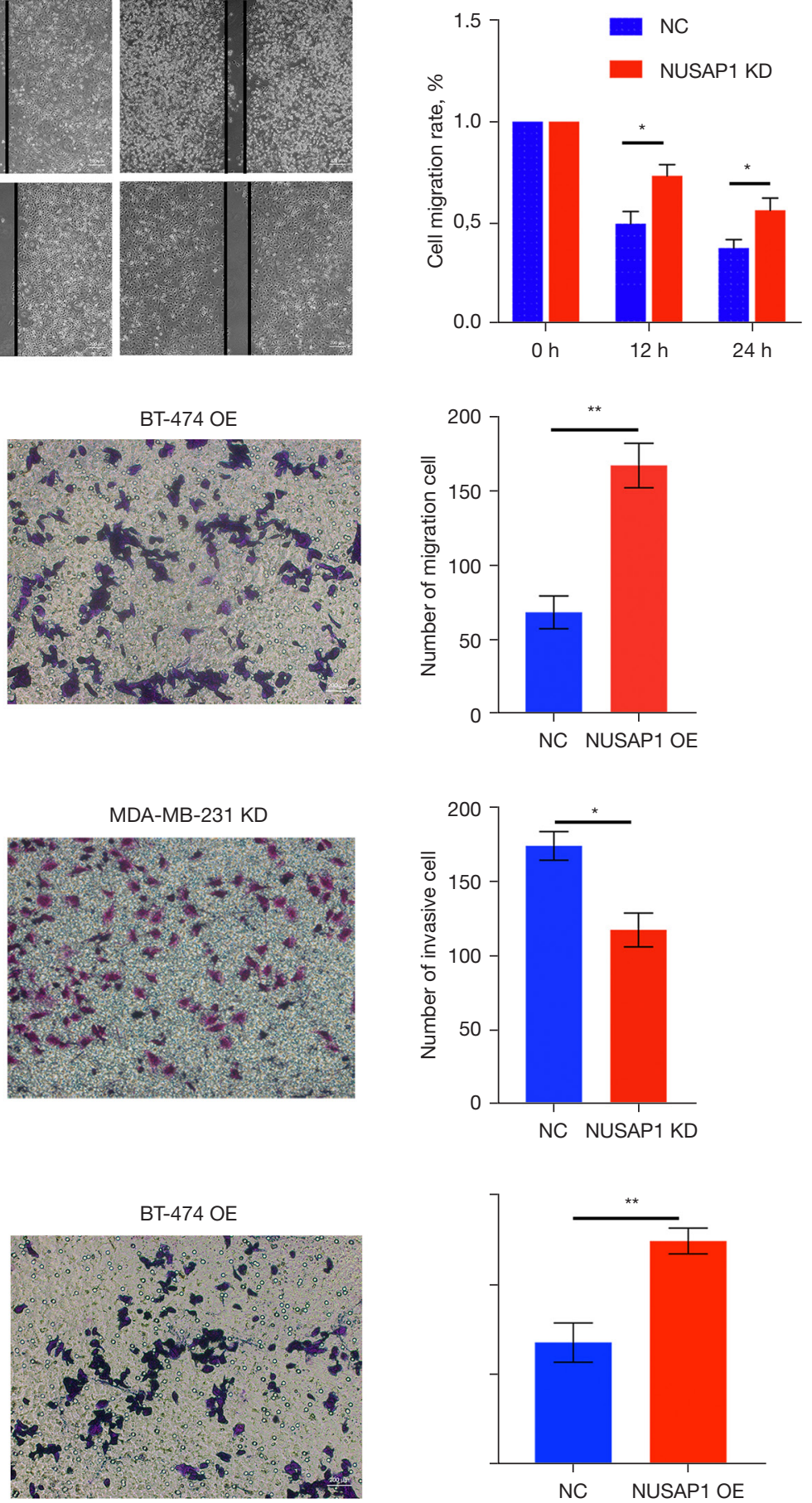

Figure 5 NUSAP1 expression regulates the breast cancer cells migration and invasion $(\times 50)$. (A) Cell migration of the MDA-MB-231 cell line via wound healing assay in NC and KD NUSAP1 group; (B) cell invasion of the MDA-MB-231 cell line via transwell assay in NC and KD NUSAP1 group; cell migration (C) and invasion (D) of the BT-474 cell line via transwell assay in NC and OE NUSAP1 group; (B-D) was determined by crystal violet staining. * $\mathrm{P}<0.05$; ${ }^{* *}, \mathrm{P}<0.01$. NUSAP1, nucleolar spindle-associated protein 1 ; NC, negative control; $\mathrm{OE}$, overexpression; KD, knockdown. 
A

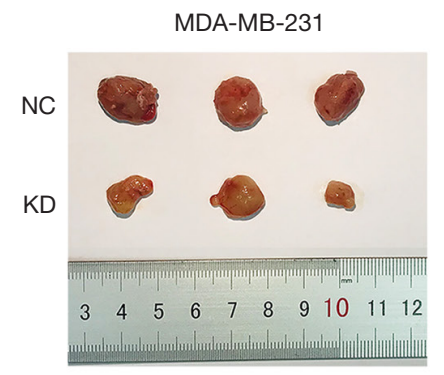

C

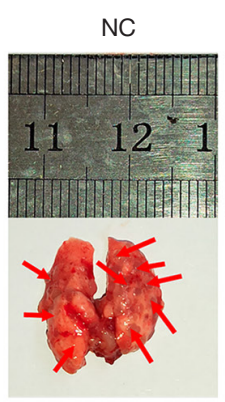

$\mathrm{KD}$

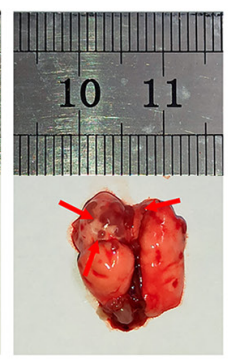

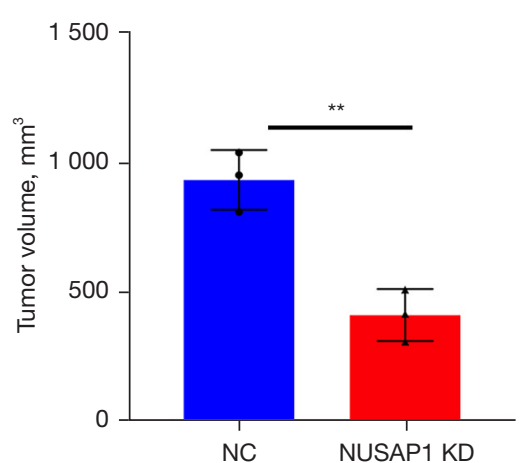

D

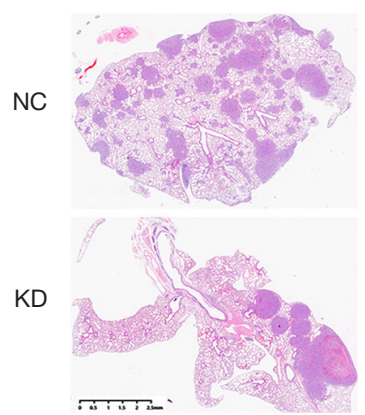

B
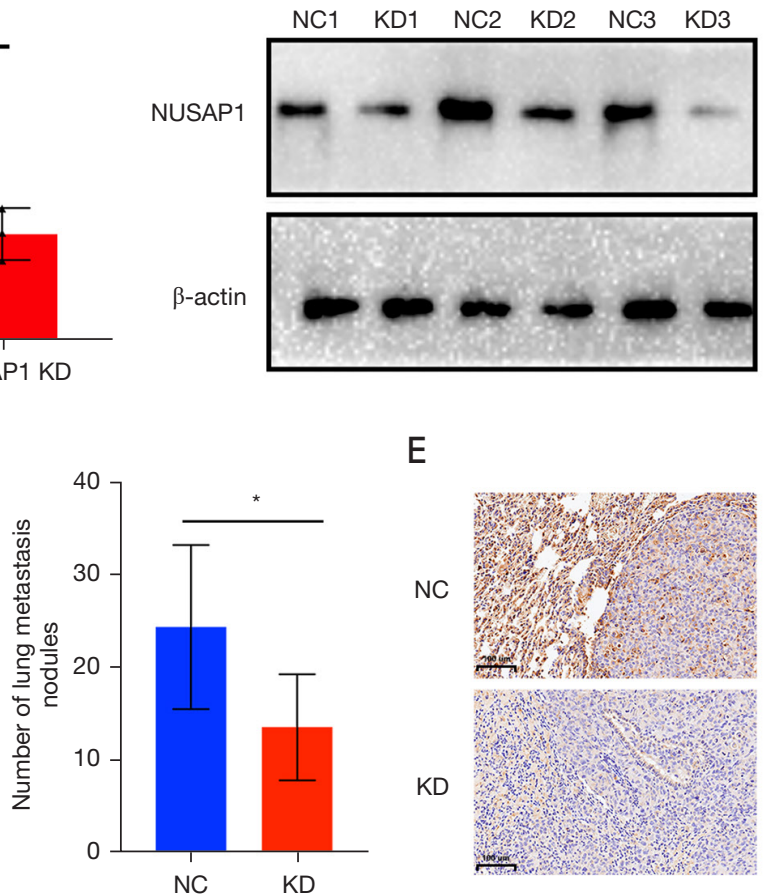

$\mathrm{E}$

NC

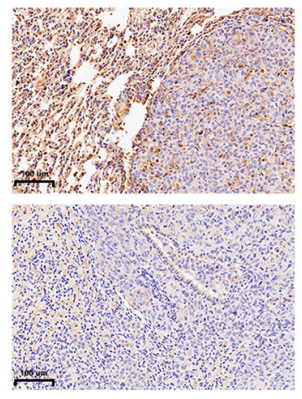

Figure 6 NUSAP1 promoted breast cancer growth and lung metastasis in vivo. (A) Representative images of xenografts and a summary of tumor weight in nude mice; (B) NUSAP1 expression in xenografts via western blot; (C) representative images of metastasis nodules (arrows) on the lung surface 8 weeks after tail vein injection of KD-NUSAP1 and NC-MDA-MB-231 cells; (D) representative images of hematoxylin and eosin staining sections derived from lung metastatic, the number of nodules was quantified in the right panel; (E) representative immunohistochemistry images of NUSAP1 expression in lung metastasis nodules, *, $\mathrm{P}<0.05$; **, $\mathrm{P}<0.01$. NUSAP1, nucleolar spindleassociated protein 1; NC, negative control; KD, knockdown.

which NUSAP1 affects breast cancer progression may be as follows. NUSAP1 affects the metabolism of breast cancer cells through the AMPK/PPAR $\gamma$ pathway, further affecting their proliferation and invasion abilities to regulate the progression of breast cancer (Figure 7C).

\section{Discussion}

The present study systematically assessed the expression of NUSAP1 in breast cancer tissues and investigated its role in the development of breast cancer. We found that NUSAP1 expression was higher in breast cancer tissues compared to adjacent tissues and that NUSAP1 was negatively correlated with OS and RFS. Interestingly, NUSAP1 expression increased with the transition from normal breast tissue to invasive breast cancer. Functionally, NUSAP1 OE promoted, while NUSAP1 KD inhibited, the proliferation of breast cancer cells in vitro and in vivo. This study demonstrated that NUSAP1 plays a critical role in breast cancer cell invasion in vitro and lung metastasis in vivo. We also found that NUSAP1 may affect the proliferation and metastasis of breast cancer through the AMPK/PPAR $\gamma$ pathway.

NUSAP 1 is a $55 \mathrm{kD}$ vertebrate protein that plays a key role in spindle assembly and normal cell cycle progression (22), and its expression is strictly regulated. When NUSAP1 expression increases abnormally, cells proliferate indefinitely (23), explains the high expression of NUSAP1 in various tumors, including breast cancer. NUSAP1 expression is associated with tumor diameter, ER status, PR status, Ki67 expression, molecular phenotypes, and lymph node metastasis. Western blot assays also showed that NUSAP1 was correlated with a cell line type. Furthermore, our study on breast cancer cell lines confirmed that NUSAP1 could significantly affect breast cancer cell proliferation. Many other studies have confirmed 


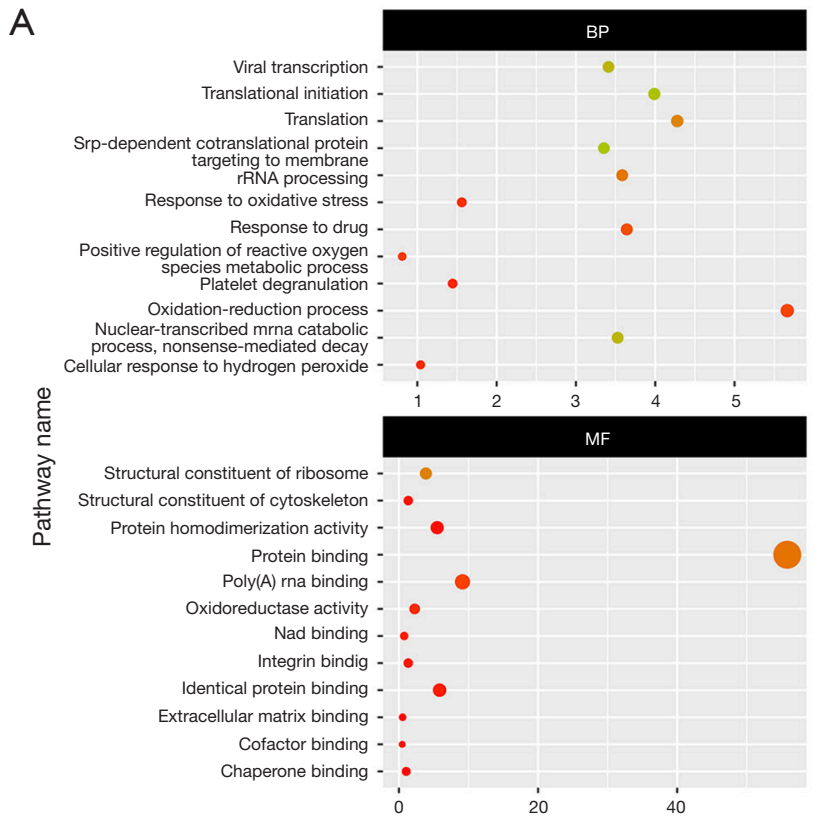

B

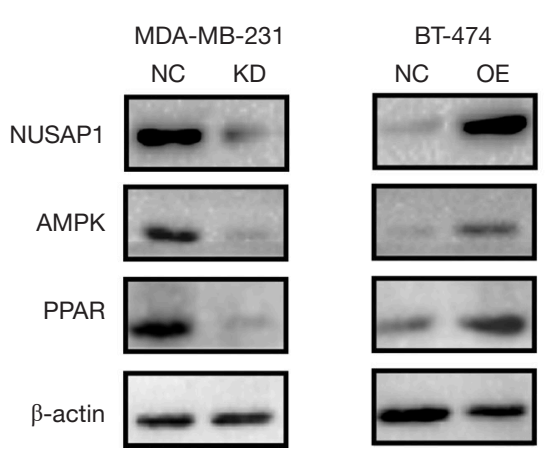

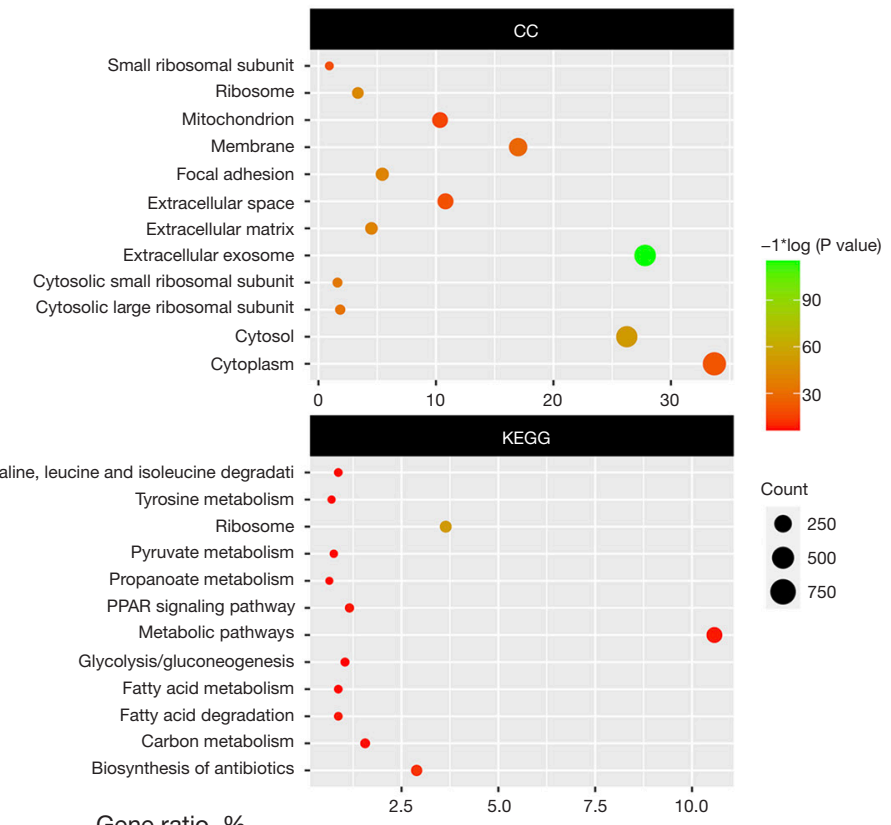

C

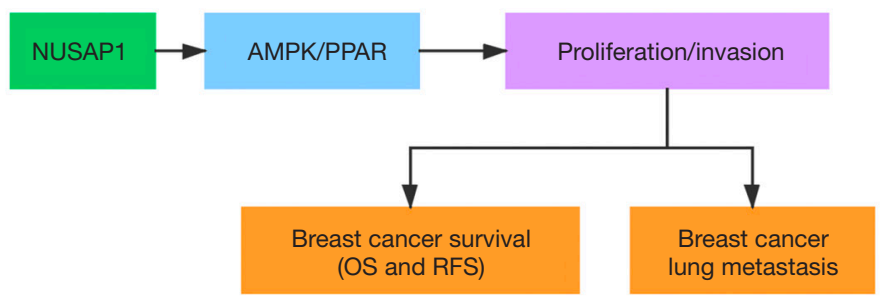

Figure 7 The promotion of NUSAP1 on breast cancer is related to AMPK signaling pathway. (A) KEGG/GO enrichment analysis showed that NUSAP1 may be related to PPAR signaling pathway in breast cancer; (B) western blot analysis of NUSAP1, AMPK and PPAR protein expression in NC and stable KD or OE NUSAP1 cell lines; (C) schematic diagram of the effect of NUSAP1 on breast cancer. BP, biological process; CC, cellular component; MF, molecular function; KEGG, Kyoto Encyclopedia of Genes and Genomes; GO, Gene Ontology; NUSAP1, nucleolar spindle-associated protein 1; NC, negative control; KD, knockdown; OE, overexpression.

that NUSAP1 could affect the growth of other cancers. For example, NUSAP1 can induce the proliferation and migration of colorectal cancer cells (5) and induce nonsmall-cell lung cancer cell growth and metastasis in vitro and in vivo (10).

In addition to cell proliferation, NUSAP1 was also involved in invasion and lymph node metastasis in breast cancer cell lines and in patients, which was confirmed in an animal study. The association between NUSAP1 and metastasis was confirmed in previous studies. For example,
NUSAP1 silencing inhibits DNMT1 to inhibit colorectal cancer cell proliferation, migration, and invasion (5). In non-small-cell lung cancer, NUSAP1 KD inhibits cell metastasis by regulating BTG2/PI3K/Akt signaling (10). Additionally, we observed that NUSAP1 was highly expressed in patients with lymph node metastasis, indicating that NUSAP1 promotes lymph node metastasis in breast cancer. Further survival analysis showed worse OS and RFS in the NUSAP1-positive group, which was confirmed in the database. All the above results support that NUSAP1 may 
be a potential therapeutic target for breast cancer.

PPAR $\gamma$ belongs to the PPAR family of nuclear hormone receptors, which regulate various biological processes, including cell differentiation, cell proliferation, and glucose and fatty acid metabolism $(23,24)$. In addition to acting as a transcription factor to regulate glycolysis and lipid metabolism to meet the energy needs of cancer cells $(25,26)$, $\operatorname{PPAR} \gamma$ can also act as a tumor protooncogene to promote tumorigenesis (27). PPAR $\gamma$ can increase ROS levels and inhibit tumor growth by regulating metabolism $(28,29)$, inducing apoptosis (29), and inhibiting the proliferation, invasion, and migration of tumor cells (30,31). As one of the targets of aspirin, AMPK plays an important role in homeostasis, autophagy, and redox balance (32). However, increasing evidence also shows that AMPK has various substrates involved in different biological processes (33) and plays an inhibitory or promoting role in various tumors (34). For example, AMPK can lead to cell cycle arrest by promoting the phosphorylation of CDKN1 and p53 (35). In addition, AMPK promotes the growth of KRAS-mutant lung cancer by activating TFE3 (36). Our study first found that PPAR $\gamma$ may play a role in the occurrence and development of breast cancer through enrichment analysis. We also found that NUSAP1 affects the proliferation and metastasis of breast cancer through AMPK/PPAR $\gamma$. This is the first study to show that NUSAP1 can promote breast cancer through the AMPK/PPAR $\gamma$ signaling pathway, which provides a new idea for targeting the NUSAP1/ AMPK/PPAR $\gamma$ axis in breast cancer research and treatment. However, in vitro experiment the animal model does not adequately represent the molecular basis for, or the clinical features of cancer metastasis.

\section{Conclusions}

In summary, we demonstrate that NUSAP1 overexpression in breast cancer promotes breast cancer proliferation and metastasis via activating the AMPK/PPAR $\gamma$ signaling pathway, which provides evidence for NUSAP1 as a diagnostic and therapeutic target for breast cancer.

\section{Acknowledgments}

Funding: This work was supported by the Department of Science and Technology of Sichuan province, China (2020YFS0199, 2021YFS0104), Chengdu Science and Technology Bureau (2019-YF05-01082-SN), and the Fundamental Research Funds for the Central Universities
(2021SCU12021).

\section{Footnote}

Reporting Checklist: The authors have completed the ARRIVE reporting checklist. Available at https://dx.doi. org/10.21037/atm-21-5517

Data Sharing Statement: Available at https://dx.doi. org/10.21037/atm-21-5517

Conflicts of Interest: All authors have completed the ICMJE uniform disclosure form (available at https://dx.doi. org/10.21037/atm-21-5517). The authors have no conflicts of interest to declare.

Ethical Statement: The authors are accountable for all aspects of the work in ensuring that questions related to the accuracy or integrity of any part of the work are appropriately investigated and resolved. The study was conducted in accordance with the Declaration of Helsinki (as revised in 2013). All patients provided their written informed consent for inclusion before they participated in the study. The study was approved by the Ethics Committee of the Sichuan University (No. [2015]108). All animal studies and procedures followed ethical guidelines and were approved by the Sichuan University Animal Ethics Committee (No. [2020]203), in compliance with the current national guidelines for Animal Welfare of China (GB/T 35892-2018) for the care and use of animals.

Open Access Statement: This is an Open Access article distributed in accordance with the Creative Commons Attribution-NonCommercial-NoDerivs 4.0 International License (CC BY-NC-ND 4.0), which permits the noncommercial replication and distribution of the article with the strict proviso that no changes or edits are made and the original work is properly cited (including links to both the formal publication through the relevant DOI and the license). See: https://creativecommons.org/licenses/by-nc-nd/4.0/.

\section{References}

1. Ferlay J, Colombet M, Soerjomataram I, et al. Cancer statistics for the year 2020: An overview. Int J Cancer 2021. [Epub ahead of print].

2. Ribbeck K, Raemaekers T, Carmeliet G, et al. A role for NuSAP in linking microtubules to mitotic chromosomes. 
Curr Biol 2007;17:230-6.

3. Ribbeck K, Groen AC, Santarella R, et al. NuSAP, a mitotic RanGTP target that stabilizes and cross-links microtubules. Mol Biol Cell 2006;17:2646-60.

4. Matsuda K, Miyoshi H, Hiraoka K, et al. Clinicopathological and prognostic value of transforming acidic coiled-coil-containing protein 3 (TACC3) expression in soft tissue sarcomas. PLoS One 2017;12:e0188096.

5. Han G, Wei Z, Cui H, et al. NUSAP1 gene silencing inhibits cell proliferation, migration and invasion through inhibiting DNMT1 gene expression in human colorectal cancer. Exp Cell Res 2018;367:216-21.

6. Chen R, Sugiyama A, Seno H, et al. Identification of modules and functional analysis in CRC subtypes by integrated bioinformatics analysis. PLoS One 2019;14:e221772.

7. Gordon CA, Gong X, Ganesh D, et al. NUSAP1 promotes invasion and metastasis of prostate cancer. Oncotarget 2017;8:29935-50.

8. Wu Y, Liu H, Gong Y, et al. ANKRD22 enhances breast cancer cell malignancy by activating the $\mathrm{Wnt} / \beta$-catenin pathway via modulating NuSAP1 expression. Bosn J Basic Med Sci 2021;21:294-304.

9. Wang T, Liu H, Pei L, et al. Screening of tumor-associated antigens based on Oncomine database and evaluation of diagnostic value of autoantibodies in lung cancer. Clin Immunol 2020;210:108262.

10. Xu Z, Wang Y, Xiong J, et al. NUSAP1 knockdown inhibits cell growth and metastasis of non-small-cell lung cancer through regulating BTG2/PI3K/Akt signaling. J Cell Physiol 2020;235:3886-93.

11. Xie Q, Ou-Yang W, Zhang M, et al. Decreased Expression of NUSAP1 Predicts Poor Overall Survival in Cervical Cancer. J Cancer 2020;11:2852-63.

12. Sun L, Shi C, Liu S, et al. Overexpression of NuSAP1 is predictive of an unfavourable prognosis and promotes proliferation and invasion of triple-negative breast cancer cells via the $\mathrm{Wnt} / \beta$-catenin/EMT signalling axis. Gene 2020;747:144657.

13. Li H, Zhang W, Yan M, et al. Nucleolar and spindle associated protein 1 promotes metastasis of cervical carcinoma cells by activating $\mathrm{Wnt} / \beta$-catenin signaling. J Exp Clin Cancer Res 2019;38:33.

14. Zhang X, Pan Y, Fu H, et al. Nucleolar and Spindle Associated Protein 1 (NUSAP1) Inhibits Cell Proliferation and Enhances Susceptibility to Epirubicin In Invasive Breast Cancer Cells by Regulating Cyclin D Kinase (CDK1) and DLGAP5 Expression. Med Sci Monit
2018;24:8553-64.

15. Györffy B, Lanczky A, Eklund AC, et al. An online survival analysis tool to rapidly assess the effect of 22,277 genes on breast cancer prognosis using microarray data of 1,809 patients. Breast Cancer Res Treat 2010;123:725-31.

16. Yoshida T, Miura T, Matsumiya T, et al. Toll-Like Receptor 3 as a Recurrence Risk Factor and a Potential Molecular Therapeutic Target in Colorectal Cancer. Clin Exp Gastroenterol 2020;13:427-38.

17. Mahadevappa R, Neves H, Yuen SM, et al. DNA Replication Licensing Protein MCM10 Promotes Tumor Progression and Is a Novel Prognostic Biomarker and Potential Therapeutic Target in Breast Cancer. Cancers (Basel) 2018;10:282.

18. Yao PL, Morales JL, Zhu B, et al. Activation of peroxisome proliferator-activated receptor- $\beta / \delta$ (PPAR- $\beta / \delta$ ) inhibits human breast cancer cell line tumorigenicity. Mol Cancer Ther 2014;13:1008-17.

19. Liu L, Zhang T, Hu J, et al. Adiponectin/SIRT1 Axis Induces White Adipose Browning After Vertical Sleeve Gastrectomy of Obese Rats with Type 2 Diabetes. Obes Surg 2020;30:1392-403.

20. Hwang JK, Yu HN, Noh EM, et al. DHA blocks TPAinduced cell invasion by inhibiting MMP-9 expression via suppression of the PPAR- $\gamma / \mathrm{NF}-\kappa \mathrm{B}$ pathway in MCF-7 cells. Oncol Lett 2017;13:243-9.

21. Xiao JB, Ma JQ, Yakefu K, et al. Effect of the SIRT3-AMPK/ PPAR pathway on invasion and migration of cervical cancer cells. Int J Clin Exp Pathol 2020;13:2495-501.

22. Kretschmer C, Sterner-Kock A, Siedentopf F, et al. Identification of early molecular markers for breast cancer. Mol Cancer 2011;10:15.

23. Peters JM, Shah YM, Gonzalez FJ. The role of peroxisome proliferator-activated receptors in carcinogenesis and chemoprevention. Nat Rev Cancer 2012;12:181-95.

24. Luo Y, Xie C, Brocker CN, et al. Intestinal PPAR $\alpha$ Protects Against Colon Carcinogenesis via Regulation of Methyltransferases DNMT1 and PRMT6. Gastroenterology 2019;157:744-759.e4.

25. Guo B, Huang X, Lee MR, et al. Antagonism of PPAR- $\gamma$ signaling expands human hematopoietic stem and progenitor cells by enhancing glycolysis. Nat Med 2018;24:360-7.

26. Mirza AZ, Althagafi II, Shamshad H. Role of PPAR receptor in different diseases and their ligands: Physiological importance and clinical implications. Eur J Med Chem 2019;166:502-13.

27. Rogenhofer S, Ellinger J, Kahl P, et al. Enhanced 
expression of peroxisome proliferate-activated receptor gamma (PPAR- $\gamma$ ) in advanced prostate cancer. Anticancer Res 2012;32:3479-83.

28. Liu YD, Yu SL, Wang R, et al. Rosiglitazone Suppresses Calcium Oxalate Crystal Binding and Oxalate-Induced Oxidative Stress in Renal Epithelial Cells by Promoting PPAR- $\gamma$ Activation and Subsequent Regulation of TGF- $\beta 1$ and HGF Expression. Oxid Med Cell Longev 2019;2019:4826525.

29. Giampietro L, Gallorini M, De Filippis B, et al. PPAR- $\gamma$ agonist GL516 reduces oxidative stress and apoptosis occurrence in a rat astrocyte cell line. Neurochem Int 2019;126:239-45.

30. Yang PL, Wang JS, Cheng XM, et al. PPAR- $\gamma$ Ligand Inhibits Nasopharyngeal Carcinoma Cell Proliferation and Metastasis by Regulating E2F2. PPAR Res 2019;2019:8679271.

31. He HP, Gu S. The PPAR- $\gamma / \mathrm{SFRP} 5 / \mathrm{Wnt} / \beta$-catenin signal

Cite this article as: Qiu J, Xu L, Zeng X, Wu Z, Wang Y, Wang Y, Yang J, Wu H, Xie Y, Liang F, Lv Q, Du Z. NUSAP1 promotes the metastasis of breast cancer cells via the AMPK/ PPAR $\gamma$ signaling pathway. Ann Transl Med 2021;9(22):1689. doi: $10.21037 / \mathrm{atm}-21-5517$ axis regulates the dexamethasone-induced osteoporosis. Cytokine 2021;143:155488.

32. Clement ST, Dixit G, Dohlman HG. Regulation of yeast $G$ protein signaling by the kinases that activate the AMPK homolog Snf1. Sci Signal 2013;6:ra78.

33. Hardie DG, Schaffer BE, Brunet A. AMPK: An EnergySensing Pathway with Multiple Inputs and Outputs. Trends Cell Biol 2016;26:190-201.

34. Vara-Ciruelos D, Russell FM, Hardie DG. The strange case of AMPK and cancer: Dr Jekyll or Mr Hyde? Open Biol 2019;9:190099.

35. Jones RG, Plas DR, Kubek S, et al. AMP-activated protein kinase induces a p53-dependent metabolic checkpoint. Mol Cell 2005;18:283-93.

36. Eichner LJ, Brun SN, Herzig S, et al. Genetic Analysis Reveals AMPK Is Required to Support Tumor Growth in Murine Kras-Dependent Lung Cancer Models. Cell Metab 2019;29:285-302.e7. 
Supplementary

Table S1 The sequences of NUSAP1 shRNAs used in this study

\begin{tabular}{ll}
\hline Gene & Sequences for shRNAs \\
\hline NUSAP1 shRNA-1 & 5'-GCACCAAGAAGCTGAGAATGC-3' \\
NUSAP1 shRNA-2 & 5'-GGAAATGGAGTCCATTGATCA-3' \\
NUSAP1 shRNA-3 & 5'- ATGAATGAACTGAAGCAGCCCA -3' \\
NC shRNA & 5'-ACTAAGTTGCGTTACACCCTT-3' \\
\hline
\end{tabular}

